\title{
Corticospinal excitability in patients with anoxic, traumatic, and non-traumatic diffuse brain injury
}

\author{
Natallia Lapitskaya ${ }^{\mathrm{a}, *}$, Sofie Kirial Moerk ${ }^{\mathrm{a}}$, Olivia Gosseries ${ }^{\mathrm{b}}$, Joergen Feldbaek Nielsen ${ }^{\mathrm{a}}$, \\ Alain Maertens de Noordhout ${ }^{\mathrm{c}}$ \\ ${ }^{\text {a }}$ Research Department, Hammel Neurorehabilitation and Research Centre, Voldbyvej 15, 8450 Hammel, Denmark \\ ${ }^{\mathrm{b}}$ Coma Science Group, Cyclotron Research Centre, University of Liege, Sart-Tilman B30, 4000 Liege, Belgium \\ ${ }^{\mathrm{c}}$ Neurology Department, University of Liège, Centre Hospitalier Regional de la Citadelle, Boulevard du 12ème de Ligne, 1. 4000 Liège, Belgium
}

\section{A R T I C L E I N F O}

Article history:

Received 12 November 2011

Received in revised form

13 February 2012

Accepted 12 March 2012

Available online $\mathrm{xxx}$

\section{Keywords:}

Brain injury

Motor evoked potential

Transcranial magnetic stimulation

Short latency afferent inhibition

\begin{abstract}
A B S T R A C T
Background: Transcranial magnetic stimulation (TMS) have been frequently used to explore changes in motor cortex excitability in stroke and traumatic brain injury, while the extent of motor cortex reorganization in patients with diffuse non-traumatic brain injury remains largely unknown.

Objective/hypothesis: It was hypothesized that the motor cortex excitability would be decreased and would correlate to the severity of brain injury and level of functioning in patients with anoxic, traumatic, and non-traumatic diffuse brain injury.

Methods: TMS was applied to primary motor cortices of 19 patients with brain injury (5 traumatic and 14 non-traumatic causes; on average four months after insult), and 9 healthy controls. The test parameters included resting motor threshold (RMT), short intracortical inhibition (SICI), intracortical facilitation (ICF), and short latency afferent inhibition (SAI). Excitability parameters were correlated to the severity of brain injury measured with Glasgow Coma Scale and the level of functioning assessed using the Ranchos Los Amigos Levels of Cognitive Functioning Assessment Scale and Functional Independence Measure. Results: The patient group revealed a significantly decreased SICI and SAI compared to healthy controls with the amount of SICI correlated significantly to the severity of brain injury. Other electrophysiological parameters did not differ between the groups and did not exhibit any significant relationship with clinical functional scores.

Conclusions: The present study demonstrated the impairment of the cortical inhibitory circuits in patients with brain injury of traumatic and non-traumatic aetiology. Moreover, the significant correlation was found between the amount of SICI and the severity of brain injury.
\end{abstract}

(c) 2012 Elsevier Inc. All rights reserved.

\section{Introduction}

Severe brain injury is a growing public health challenge [1]. The great heterogeneity of pathophysiological mechanisms that comprise the spectrum of diffuse and focal brain injuries requires a combined approach to electrophysiological assessment of brain function in these challenging patients. Somatosensory evoked potentials (SEPs) are widely used for evaluation of sensory pathways and outcome prognosis in severe brain injury, although the prognostic value of SEPs is highly dependent on aetiology of injury

The authors report no economical conflicts of interest.

NL is supported by the European Neurological Society Fellowship and Danish Medical Research Council. OG is supported by the Belgian National Funds for Scientific Research (FNRS).

* Corresponding author. Natallia Lapitskaya, Research Department, Hammel Neurorehabilitation and Research Centre, Voldbyvej 15, 8450 Hammel, Denmark.

E-mail address: natlap@rm.dk (N. Lapitskaya).
[2,3]. During the last two decades, motor evoked potentials (MEPs) following single-pulse or paired-pulse transcranial magnetic stimulation (TMS) have become an objective means for the assessment of motor cortex excitability and the integrity of motor pathways [4]. Application of single-pulse TMS in comatose patients might improve the assessment of motor dysfunction, but have no prognostic value for the long-term outcome [5]. Several studies indicate that cortical injuries, independent of their aetiology, can lead to a reduced strength of inhibitory neurotransmission [6-8]. The lesion-induced abnormal cortical excitability has been reported in the affected $[6,7,9]$ and unaffected hemisphere $[10,11]$ in patients with stroke. Cortical excitability, assessed using paired-pulse TMS, is shown to correlate with the severity of brain damage in patients with diffuse traumatic brain injury (TBI) [12-16]. Paired TMS has been proposed as a tool for predicting outcome after stroke [17] as well as predicting functional outcome after rehabilitation interventions [18]. Normalization of amplitude and waveform of MEPs 
and motor threshold (MT) was related to the clinical recovery in mild to moderate TBI [19]. Despite this, studies identifying changes in cortical excitability in patients with diffuse non-traumatic brain injury due to subarachnoidal haemorrhage and anoxia are rare, and the extent of motor cortical reorganization in these patients remains largely unknown. Moreover, we wanted to assess the relationship between paired TMS measures in the motor cortex and the clinical measures of the overall functional status and the level of consciousness. In order to test the excitability in the motor cortex, we studied (1) Resting motor threshold (RMT), as a measure of membrane excitability and anatomical features related to corticospinal tract function [20]; (2) Intracortical inhibition (SICI) and facilitation (ICF), as a measure of cortical inhibitory network depended on GABAA receptor activity [21,22]; and (3) Short latency afferent inhibition (SAI) $[23,24]$, as a cortical inhibitory phenomenon thought to be regulated by cholinergic circuits [25].

\section{Hypothesis}

It was hypothesized that the motor cortex excitability would be decreased and would correlate to the severity of brain injury and level of functioning in patients with anoxic, traumatic, and nontraumatic diffuse brain injury.

\section{Methods}

\section{Patients and controls}

Nineteen patients with severe brain injury (trauma, $n=5$; anoxic-ischaemic encephalopathy, $n=3$; subarachnoidal haemorrhage, $n=10$; infection, $n=1 ; 8$ males; mean age (SD): 50.5 years [12]; mean time since injury (SD): 4.4 months (2.6), and nine healthy volunteers ( 5 males; mean age SD: 49.6 years [18]) were tested. Patients were recruited from Hammel Neurorehabilitation and Research Centre in Denmark. Inclusion criteria were: brain injury due to trauma, cardiac arrest, subarachnoidal haemorrhage or infection, which required intensive multidisciplinary inpatient rehabilitation due to moderate to severe cognitive impairment and/ or motor deficit bilaterally after discharge from the acute hospital. Exclusion criteria were: history of other neurological or psychiatric diseases, alcohol or drug abuse, presence of other major medical illness. Patients were examined with computed tomography and/or magnetic resonance imaging during the hospitalization, time between neuroimaging and TMS examination was on average $1.9 \pm 1.9$ months after injury. All patients were scanned on the admission to the acute hospital and neuroimaging examination was afterwards repeated individually and determined by clinical needs. The following morphological diagnoses were made according to neuroimaging evaluation: no pathological funds (16\%), focal lesion (79\%), subarachnoid haemorrhage (58\%), diffuse axonal injury (21\%), hydrocephalus (37\%); $84 \%$ of patients had more than one pathology. No sedative medication was administered prior to the TMS measurements. Eight patients were treated without neuroactive drugs, nine patients with one neuroactive drug (e.g. serotonin reuptake inhibitors $(n=2)$, adrenergic receptor inhibitors NaSSA $(n=5)$, and methylphenidate $(n=2))$, and two patients with combination of valproic acid and clonazepam $(n=2)$. Demographic and clinical patient characteristics are summarized in Table 1. All participants were screened in order to ensure they weren't contraindicated to TMS [26]. This study was approved by the Central Denmark Region Committees on Biomedical Research Ethics, Denmark (M-20080063). Thirteen patients and all healthy participants gave written informed consent. For six patients informed written consent was obtained from the patients appointed 'consultee' as defined by the Mental Capacity Act (2005); in all cases this was the patient's legal guardian and the family doctor.

\section{Clinical assessment}

To assess the severity of brain injury we recorded the lowest Glasgow Coma Scale (GCS) [27] from the patients' acute medical charts. Within the first week after admission to the rehabilitation centre the experienced interdisciplinary team (physiotherapist, occupational therapist, and neuropsychologist) performed clinical assessment of patients with Rancho Los Amigos Level Cognitive Function Scale (RLAS) [28], and Functional Independence Measure (FIM) [29].

\section{Somatosensory evoked potentials}

SEPs were registered from both hemispheres with "VikingQuest" (Viasys Healthcare, USA) from the active skin electrodes attached $3 \mathrm{~cm}$ posterior to C3 and C4 (10-20 system) respectively for the right and left median nerve, and with the reference electrode placed at Fz. A bipolar electrical stimulator was used. Test parameters were: stimulus duration $0.2 \mathrm{~ms}$; frequency $2 \mathrm{~Hz}$; intensity: $150 \%$ over the motor threshold for abductor policis brevis muscle. Five hundred responses were averaged to identify the latency of the $\mathrm{N} 20$ peak.

\section{Transcranial magnetic stimulation}

Magnetic stimulation was performed with a Magstim 200 (The Magstim Company Ltd, U.K.) and a Magstim figure-of-eight-shaped coil with external loop diameters of $9 \mathrm{~cm}$. Both hemispheres were stimulated in patients and healthy subjects, except in one patient where the study was stopped halfway because patient showed signs of fatigue and discomfort. Electromyographic (EMG) activity was recorded from contralateral first dorsal interossei (FDI) muscle with two $9 \mathrm{~mm}$ diameter $\mathrm{Ag}-\mathrm{AgCl}$ surface electrodes in a belly tendon montage. EMG activity was registered with a "Viking Select" device (Viasys Healthcare, USA), amplified and filtered (band pass: $10 \mathrm{~Hz}-3000 \mathrm{~Hz}$ ), and stored on a computer for off-line analyses. Initially, maximum muscle response $\left(M_{\max }\right)$ and F-waves were measured from FDI after ulnar nerve stimulation ( $0.2 \mathrm{~ms}$ squarewave constant current pulses) at the wrist. M-wave amplitude was measured peak-to-peak. F-wave persistence was defined as number of potentials with amplitude of at least $20 \mu \mathrm{V}$ out of 20 recordings [30]. For TMS experiments subjects wore a close-fitting cap with a $1-\mathrm{cm}$ grid to ensure constant coil position during the entire session. The coil was always held tangentially to the head with the handle pointing backwards and $45^{\circ}$ laterally from the midline [31]. The coil was placed at the cranial site from which a maximum FDI response was obtained (hotspot). The RMT, expressed as a percentage of the maximum stimulator output, was defined as the intensity needed to produce a response of $50 \mu \mathrm{V}$ (peak-to-peak) or more in at least five of ten consecutive stimuli in the relaxed muscle [32]. Paired-pulse stimulation to measure SICI and ICF was performed according to previously published protocol [33]. The conditioning magnetic stimulus was $80 \%$ of the RMT, and the test stimulus had an intensity resulting in an unconditioned MEP (uMEP) of $\sim 1 \mathrm{mV}$. Interstimuli intervals (ISI) were $2,3,10$, and 15 ms. Each TMS block consisted of 25 pseudorandomised stimuli: 5 single magnetic stimuli and 5 stimuli at each ISI; the interval between each stimulus was $8 \mathrm{~s}$. MEP amplitudes at different ISI's were calculated as a percentage of the mean amplitude of the test pulse alone. SAI was measured in the relaxed muscle by pairedpulse stimulation paradigm [23]. Conditioning stimuli were $0.2 \mathrm{~ms}$ single pulses of electrical stimulation applied through 
Table 1

Demographic and clinical patient characteristics.

\begin{tabular}{|c|c|c|c|c|c|c|c|c|c|}
\hline $\begin{array}{l}\text { Patient } \\
\text { number }\end{array}$ & $\begin{array}{l}\text { Age } \\
\text { (years) }\end{array}$ & Gender & Brain injury cause & $\begin{array}{l}\text { Time since } \\
\text { insult (days) }\end{array}$ & $\begin{array}{l}\text { GCS (minimum } \\
\text { total score) }\end{array}$ & $\begin{array}{l}\text { RLAS (maximum } \\
\text { total score) }\end{array}$ & $\begin{array}{l}\text { FIM (maximum } \\
\text { total score) }\end{array}$ & Motor function, hand & Neuroimaging (CT or MRI) \\
\hline 1 & 63 & $\mathrm{M}$ & Cardiac arrest & 107 & $\mathrm{NA}$ & 8 & 54 & Moderate paresis bilaterally & Normal \\
\hline 2 & 51 & M & $\mathrm{SAH}$ & 71 & 9 & 7 & 117 & No motor deficit & $\begin{array}{l}\text { Severe basal SAH (ACA and AP; clips, craniotomy), ventricular } \\
\text { enlargement, VP-shunt }\end{array}$ \\
\hline 3 & 41 & $\mathrm{~F}$ & Cardiac arrest & 125 & NA & 6 & 48 & $\begin{array}{l}\text { Moderate paresis bilaterally, } \\
\text { myoclonus }\end{array}$ & Normal \\
\hline 4 & 49 & M & TBI & 152 & 11 & 8 & 115 & No motor deficit & Multiple small haemorrhages frontal area bilaterally \\
\hline 5 & 34 & M & $\mathrm{SAH}$ & 212 & 3 & 7 & 118 & No motor deficit & $\begin{array}{l}\text { Severe SAH (ACA; clips and coil; R craniotomi), oedema R frontal, } \\
\text { ventricular enlargement, no VP-shunt. }\end{array}$ \\
\hline 6 & 20 & M & TBI & 144 & 10 & 8 & 122 & No motor deficit & $\begin{array}{l}\text { Traumatic SAH, multiple subcortical haemorrhages fronto-parietal } \\
\text { ilaterally }\end{array}$ \\
\hline 7 & 59 & $\mathrm{~F}$ & SAH & 119 & 3 & 6 & 107 & No motor deficit & Central SAH (AB; coil) \\
\hline 8 & 49 & M & TBI & 125 & 3 & 6 & 23 & $\begin{array}{l}\text { Right severe paresis, left } \\
\text { moderate paresis }\end{array}$ & Ischemic lesions $\mathrm{L}$ cerebellum, $\mathrm{L}$ pons and $\mathrm{L}$ medulla oblongata \\
\hline 9 & 39 & M & TBI & 100 & 10 & 6 & 120 & No motor deficit & Severe contusions with oedema $\mathrm{L}$ temporal and frontal, $\mathrm{R}$ temporal \\
\hline 10 & 54 & $\mathrm{~F}$ & SAH & 73 & 4 & 3 & 20 & Severe paresis bilaterally & Severe SAH (AB; coil), ventricular enlargement, L VP-shunt \\
\hline 11 & 65 & $\mathrm{~F}$ & $\mathrm{SAH}$ & 120 & 6 & 3 & 18 & Severe paresis bilaterally & $\begin{array}{l}\text { Severe SAH (ACA; clips), infarcts parietal bilaterally, ventricular } \\
\text { enlargement, R VP-shunt }\end{array}$ \\
\hline 12 & 49 & $\mathrm{~F}$ & Cardiac arrest & 51 & NA & 7 & 86 & No paresis, myoclonus & Normal \\
\hline 13 & 47 & $\mathrm{~F}$ & SAH & 103 & 5 & 5 & 32 & Moderate paresis bilaterally & Severe SAH (ACA; clips), infarcts parasagital frontal bilaterally \\
\hline 14 & 63 & $\mathrm{~F}$ & SAH & 64 & 3 & 7 & 93 & Moderate paresis bilaterally & $\begin{array}{l}\text { Severe SAH (AB; coil, external drainage), ventricular enlargement, } \\
\text { no VP-shunt }\end{array}$ \\
\hline 15 & 56 & $\mathrm{~F}$ & SAH & 86 & 11 & 6 & 92 & No motor deficit & Severe SAH (AP; clips), infarcts parasagitalt $R$ frontal \\
\hline 16 & 66 & $\mathrm{~F}$ & $\mathrm{SAH}$ & 342 & 4 & 4 & 21 & Severe paresis bilaterally & $\begin{array}{l}\text { SAH, infarcts L temporal and occipital; } \mathrm{L} \text { cerebral peduncle, } \\
\text { cerebellum, iskaemic lesions frontal and parietal bilaterally, } \\
\text { ventricular enlargement, no VP-shunt. }\end{array}$ \\
\hline 17 & 62 & $\mathrm{~F}$ & $\mathrm{SAH}$ & 36 & 3 & 3 & 18 & Severe paresis bilaterally & $\begin{array}{l}\text { Severe SAH (ACA; clips), infarcts frontal bilaterally, R occipital, } \\
\text { iskaemic lesions periventricular deep white matter }\end{array}$ \\
\hline 18 & 48 & $\mathrm{~F}$ & $\begin{array}{l}\text { Hypophysis adenoma/ } \\
\text { postoperative infection }\end{array}$ & 243 & 4 & 2 & 18 & Severe paresis bilaterally & Ventricular enlargement, hygroma R frontal, L VP-shunt \\
\hline 19 & 25 & M & TBI & 249 & 3 & 8 & NA & No motor deficit & $\begin{array}{l}\text { Diffuse axonal injury, haemorrhage } \mathrm{R} \text { frontotemporal, } \mathrm{L} \text { thalamus } \\
\text { and mesencephalon }\end{array}$ \\
\hline \multicolumn{10}{|c|}{$\begin{array}{l}\text { TBI, traumatic brain injury; SAH, subarachnoidal haemorrhage; GCS, Glasgow Coma Scale: three sub-scales: motor, verbal, arousal functions (minimum score } 3 \text {, maximum } 15 \text { ); RLAS, Ranchos Los Amigos Levels of Cognitiv } \\
\text { Functioning Assessment Scale: } 1=\text { no response, } 2=\text { generalized response, } 3=\text { localized response, } 4=\text { confused, agitated response, } 5=\text { confused, inappropriate, nonagitated response, } 6=\text { confused, appropriate respons } \\
7=\text { automatic, appropriate response, } 8=\text { purposeful, appropriate response; FIM, Functional Independence Measure }: 18 \text { items are grouped into seven sub-scales: self-care, sphincter control, mobility, locomotion, commu } \\
\text { nication, psychological adjustment, and cognitive functions (minimum score } 18 \text {, maximum 126); NA, not assessed; ACA, anterior communicating artery; AP, posterior artery; AB, basilar artery; VP, ventriculo-peritoneal shun } \\
\text { R, right; L, left. }\end{array}$} \\
\hline
\end{tabular}


Table 2

Electrophysiological and single-pulse TMS measures.

\begin{tabular}{|c|c|c|c|c|}
\hline Test, mean \pm SD & Healthy, dominant hand & Healthy, non-dominant hand & Patients, dominant hand & Patients, non-dominant hand \\
\hline$M_{\max }(\mathrm{mV})$ & $13.5 \pm 4.3$ & $14.0 \pm 3.1$ & $10.5 \pm 5.8$ & $9.5 \pm 5.7$ \\
\hline F-wave persistence (number) & $18 \pm 5$ & $19 \pm 6$ & $19 \pm 4$ & $19 \pm 1$ \\
\hline MEP latency (ms) & $23.0 \pm 1.4$ & $23.6 \pm 1.8$ & $23.6 \pm 1.7$ & $22.6 \pm 1.4$ \\
\hline PMCT (ms) & $16.3 \pm 1.2$ & $16.2 \pm 1.2$ & $16.04 \pm 1.5$ & $16.03 \pm 1.4$ \\
\hline CMCT (ms) & $7.3 \pm 1.2$ & $6.8 \pm 1.4$ & $7.4 \pm 1.3$ & $6.7 \pm 0.9$ \\
\hline RMT (\% MSO) & $47.8 \pm 7.6$ & $52.2 \pm 13$ & $45.6 \pm 6.8$ & $47.1 \pm 12.7$ \\
\hline uMEP (mV) & $1.4 \pm 1.2$ & $1.4 \pm 1.4$ & $1.2 \pm 1.1$ & $1.3 \pm 0.5$ \\
\hline
\end{tabular}

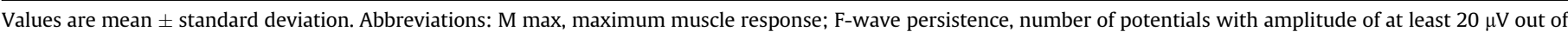

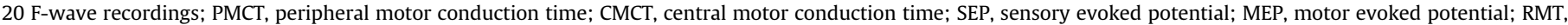
resting motor threshold; MSO, maximal stimulator output; uMEP, unconditioned MEP to the single magnetic test stimulus.

bipolar electrodes to the median nerve at the wrist with the cathode positioned proximally. The intensity of the stimuli was set at $150 \%$ over the motor threshold for abductor policis brevis muscle [23], and the magnetic test stimulus had an intensity resulting in uMEP of $\sim 1 \mathrm{mV}$. ISI's were determined relatively to the latency of the N20 component of the SEP: $\mathrm{N} 20-2 \mathrm{~ms}$, N20 $+0 \mathrm{~ms}$, $\mathrm{N} 20+2 \mathrm{~ms}, \mathrm{~N} 20+4 \mathrm{~ms}, \mathrm{~N} 20+6 \mathrm{~ms}, \mathrm{~N} 20+8 \mathrm{~ms}, \mathrm{~N} 20+15 \mathrm{~ms}$. Each TMS block consisted of 40 pseudorandomised stimuli: 5 single magnetic stimuli and 5 stimuli at each ISI; the interval between each stimulus was $8 \mathrm{~s}$.

\section{Statistical analysis}

The analyses were performed using the statistical package STATA (Stata version 9.2, Texas, U.S.A.). All electrophysiological parameters were analysed separately; comparison between the parameters obtained from different hemispheres was performed using a Wilcoxon matched-pairs signed-ranks tests; parameters of patient group were compared with those of the controls by means of Mann-Whitney tests. Comparisons between the time courses of the conditioning effect (magnetic stimulation in the paired-pulse SICI and ICF protocol and electrical stimulation at the wrist in the SAI protocol) at different ISI's in different groups (patients and controls) were made using a two factor repeated measures analysis of variance (ANOVA) with ISI and group as the main factors (and the interaction between them). A statistical difference in the ANOVAs was followed by post hoc two-sample $t$-tests on mean data from patients and controls. Data in the 2 and $3 \mathrm{~ms}$ ISI and 10 and $15 \mathrm{~ms}$ ISI were pooled for statistical analysis [34]. MEP data were logarithm transformed in order to achieve normal distribution. The relationship between clinical scores and electrophysiological parameters were evaluated using a Spearman's correlation coefficient. Statistical significance levels were set to $P=0.05$.

\section{Results}

\section{Basic electrophysiological measures}

Basic electrophysiological measures ( $M_{\max }$, F-wave persistence, PMCT, CMCT, SEP, and MEP latencies) and TMS parameters (RMT, SICI, ICF, and SAI) were not different between the dominant and non-dominant hemisphere in patients or controls $(P>0.05$, Table 2). Therefore further statistical analyses between patient and control groups were performed on parameters obtained from the dominant hemisphere.

\section{SICI and ICF}

Examples of uMEP and SICI/ICF are given in Fig. 1A and C.

Comparisons between time courses of the conditioning effect at different ISI's in patients and healthy controls revealed significant difference between these two groups $(F(3,74)=6.55, P=0.0005)$. SICI was reduced in patients compared to healthy controls
(73.4\% $\pm 43.7 \%$ in patients compared to $33.4 \% \pm 22.2 \%$ of the test response in healthy controls, $P=0.02)$. No difference was observed in the ICF parameters $(P>0.05)$, see Fig. 2 . GCS was correlated to the amount of SICI (Spearman's rho $=-0.59, P=0.0181$ ). No correlation was found between SICI and RLAS (Spearman's rho $=-0.17, P=0.5$ ) or FIM (Spearman's rho $=-0.44, P=0.065$ ), see Fig. 3 .

\section{SAI}

Comparisons between time courses of the conditioning effect at different ISI in patients and healthy controls revealed significant difference between these two groups $(F(6,156)=2.82, P=0.012)$. The responses were inhibited in healthy controls with the most pronounced inhibition when the median nerve stimulus was given at $\mathrm{N} 20+2 \mathrm{~ms}$ before the TMS stimulus $(P=0.004)$. At this ISI interval the amount of inhibition was $84.5 \pm 40.6 \%$ of the test size in patients and $49.5 \pm 27.2 \%$ of the test size in controls, with a significant difference between the groups $(P=0.027)$, see Fig. 4 . Examples of uMEP and SAI at N20 +2 ms are given in Fig. 1B and D.

We found no correlation between SAI and clinical scores (Spearman's rho $=0.02, P=0.93$ for GCS; $0.16, P=0.54$ for FIM; $-0.07, P=0.76$ for RLAS).

\section{Discussion}

The current study evaluated several excitatory and inhibitory phenomena in patients with anoxic, traumatic, and non-traumatic diffuse brain injury, and showed that, SICI and SAI showed significant differences between patients and healthy controls (while the RMT and ICF was not altered). In addition, the findings revealed a relationship between $\mathrm{SICI}$ and the severity of brain injury.

The relationship between changes in SICI/ICF and motor cortex plasticity has been investigated in the human motor cortex in different conditions. Our results are in agreement with several paired TMS studies reporting a significant decrease in SICI in the affected hemisphere in stroke patients in the acute phase and in the early stages of recovery $[10,11,35,36]$. Additionally, Di Lazzaro et al. [37] demonstrated that through theta burst stimulation there was a reduction in the MT, an increase in the MEP amplitude, and a reduction in SICI in the affected hemisphere of stroke patients. On the contrary, no changes were found in SICI in patients with diffuse TBI two years after the injury [12]. The discrepancy in the results between the current study and previous studies could be explained by the aetiology of the brain injury and the shorter period after the insult in our study population. The lesion-induced suppression of inhibition develops as fast as one day after the lesion induction [7,9], reaches a peak in the first week post lesion, and slowly and only partially recovers to a subnormal level two months after the lesion induction [6]. The acute contralesional disinhibition also seems to normalize over time [10,11].

In the current study, a significant relationship was found between SICI and the severity of brain injury. Our findings confirm the results 
A

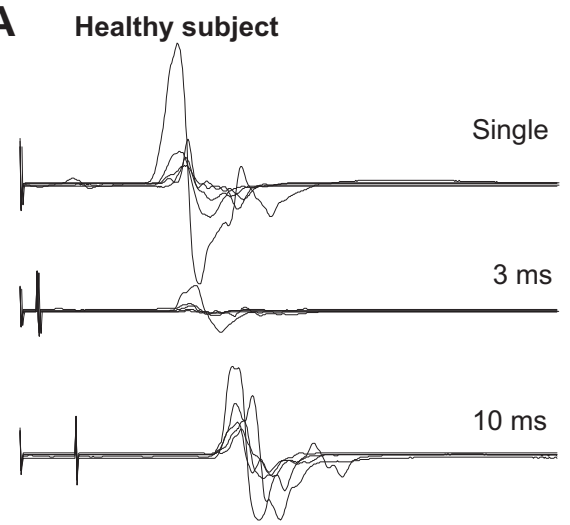

B

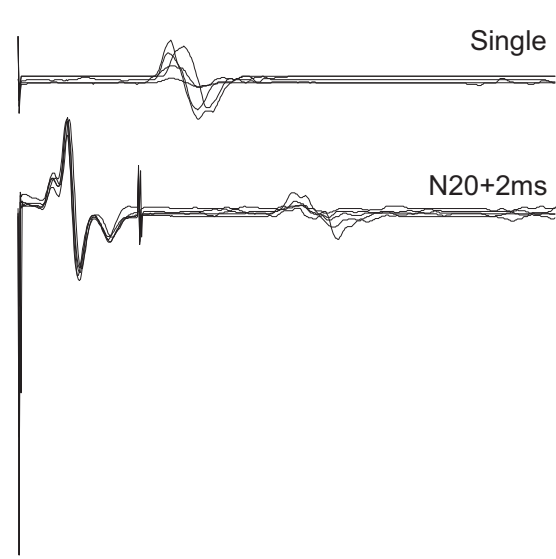

C Patient $\mathrm{nr} 4$

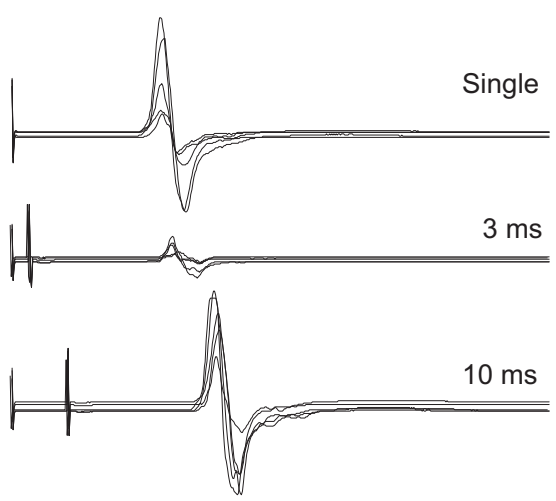

D

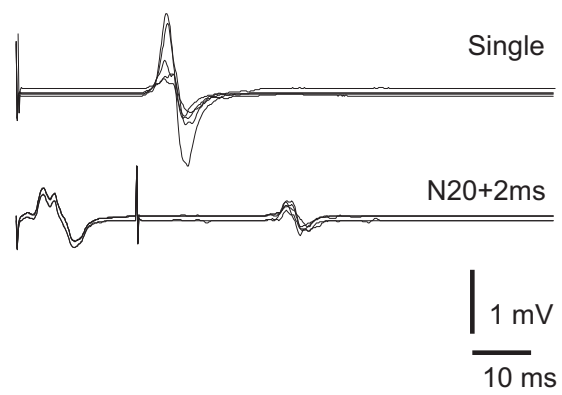

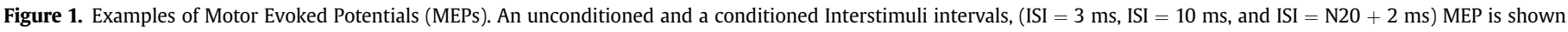
from a healthy control (A and B) and a patient ( $C$ and $D)$.

of Takeuchi et al. [15] showing a strong correlation of GCS with the cortical inhibition in patients with TBI. However, we observed no statistically significant correlations between SICI and SAI parameters and the cognitive and functional level of the patient assessed using the RLAS and FIM. Also, Di Lazzaro et al. [37] showed that an increase in MEP amplitude significantly correlated with recovery at 6 months following stroke, while the amount of SICI did not predict long-term recovery. However, it was shown that behavioural gains in motor function induced by somatosensory stimulation of the paretic hand were accompanied by a reduction in SICI and ICF in the ipsilesional primary motor area in patients with chronic stroke [38]. Due to the small sample size in the current study, the possible explanation for the lack of correlation between neurophysiological measures and clinical scores could be that the respective scores (i.e. RLAS and FIM) are not sensitive enough to characterize the diversity and the multiplicity of physical and cognitive impairments in each individual patient. Therefore, the changes in intracortical inhibition and correlation with function at any particular time point may be highly dependent on the initial patient characteristics [10,11,39]. For example, in the current study, patient no.7 with the severe brain injury due to subarachnoidal haemorrhage (GCS of 3 point in the acute period), showed pronounced SICI and remarkable functional improvement approximately 4 months after injury (FIM of 107 points at the discharge). Further studies with more homogeneous populations and more detailed and complex physical and neuropsychological examinations would provide more information about the clinical correlates and relevance of the excitability changes in patients with brain injury.
Pharmacological studies have confirmed that SICI depends on GABA receptor activity $[22,40]$. Several studies indicate that cortical injuries, independent of their aetiology, can also lead to a reduced strength of GABA-mediated inhibitory transmission [6-9]. The reduced inhibition seems to be a general phenomenon taking place as a consequence of widespread neuronal death [41]. The loss of inhibition in the affected hemisphere could be a compensatory mechanism, which may represent an adaptive form of plasticity in the motor cortex $[10,35,42,43]$, facilitating motor recovery [36]. Additionally, functional recovery is likely to be related to changes in distributed neuronal networks rather than in individual cortical regions $[44,45]$. Interhemispheric inhibition is likely altered after stroke [46]. Therefore, in future studies local changes in excitability in motor areas and assessment of interhemispheric inhibitory phenomena should be assessed. The present study showed also a significantly decreased SAI in brain injury patients compared to healthy controls. Our findings are in line with the results of Fujiki et al. [12] demonstrating decreased SAI in patients with diffuse TBI. Hypothesis of the impaired cholinergic neuronal function in brain injury is also supported by the preliminary evidence that donepezil improves memory during post acute brain injury rehabilitation $[47,48]$. The mechanisms behind reduced SAI in brain injury is unclear, but could involve either direct inhibition of motor cortex from fast conducting afferents, or withdrawal of tonic facilitation from other structures, such as thalamus [49]. Another possibility is that the subcortical lesions interrupt ascending cholinergic axons determining cortical cholinergic denervation as it was previously suggested for patients with multi-infarcts [50]. Cholinergic axons 
Paired-pulse Stimulation

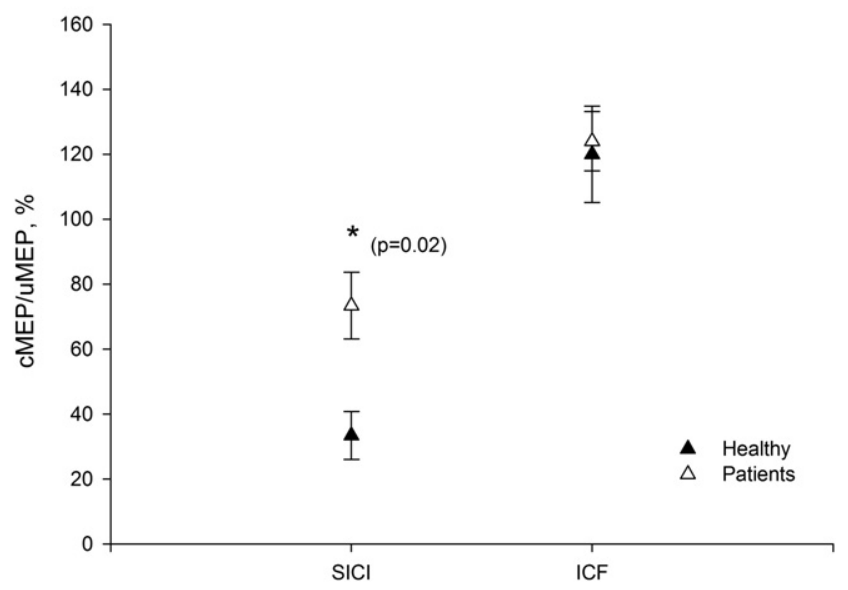

Figure 2. Short intracortical inhibition (SICI) and facilitation (ICF) in patients (open triangle) and healthy controls (closed triangle). SICI was decreased in patients compared to healthy controls $(P=0.02$, two-sample $t$-test). No significant difference was observed for the ICF parameters $(P>0.05)$. Abbreviations: MEP, motor evoked potential; uMEP, unconditioned MEP to the single magnetic test stimulus; cMEP, conditioned MEP to the paired magnetic test stimulus. Values are mean \pm SEM.

reach the cerebral cortex through the pathways that travels in the cingulum and in the external capsule [51], which makes the cortico - subcortical cholinergic circuit particularly vulnerable to the white matter damage. The resulting disconnection of cortical areas from their source of cholinergic innervation in the basal forebrain could be responsible for cognitive impairment in brain injury [52]. However, it cannot be ruled out that SAI occurs via cholinergic modulation of inhibitory circuits rather than via a direct inhibitory cholinergic effect [25,53]. Studies in rat auditory cortex [54] showed that spontaneous Ach (acetylcholine) release depresses synaptic potentials mediated by glutamate and GABA, and ACh release is in turn under glutamatergic afferent control. In humans, muscarinic antagonist (i.e. scopolamine and atropine) was shown to enhance motor cortex excitability in normal subjects $[55,56]$. Some benzodiazepines can reduce SAI [57], which might suggest GABAA circuits to be involved in SAI modulation. The major suggestion about clinical relevance of SAI comes from studies in patients with cognitive impairment due to dementia. SAI was found to be reduced in patients with Alzheimer's disease [25,58], but to be normal in non-cholinergic forms of dementia, such as frontotemporal and vascular dementia [53,59] and in patients affected by minor cognitive impairment, a level of cognitive functioning that reflects an intermediate state between normal age and Alzheimer's disease [60].

In the current study, patients with brain injury exhibited normal RMT and did not show significant laterality. Our results are in agreement with the study showed normal RMT and CMCT in chronic TBI patients without motor deficits [15]. Although, Fujiki et al. [12] observed a slight increase in RMT in diffuse TBI, which was suggested to be related to the dysfunction of the injured axon, this increase was not significant. The normal MEP latency, CMCT and RMT might indicate that patients with brain injury had only minimal or no loss of motor cortex excitability and conduction in the pyramidal tract. The previous observations made with conventional MEPs showed that motor deficit can exist in the presence of normal cortico-motoneuronal conduction times, showing that intactness of these connections is not a sufficient condition for preservation of voluntary motor activities [61]. Furthermore, absence of voluntary movements in patients with severe brain injury did not invariably predicate an abnormal RMT and CMCT [62]. This might indicate the selective involvement of the small pyramidal tract neurons with a relative sparing of the large fast conducting corticospinal fibres that are responsible for MEP [63]. For the detection of the failure of corticospinal tract conduction, the triple stimulation technique, which consists of one transcranial magnetic and two peripheral electric stimuli (plexus and nerve) delivered along the motor pathways, might have higher sensitivity than conventional MEP or CMCT testing [64]. In contrast to these results, a higher RMT is reported in patients with moderate focal TBI, while no difference was found between patients with minor or moderate diffuse TBI $[13,19]$. The authors have also described some improvement in the observed high RMT in the three-months follow-up study [19]. Our findings of normal RMT in brain injury patients could firstly be explained by that fact, that the period after the insult was longer in our study (on average 4 months); secondly, that the majority of the included patients suffered from a non-traumatic brain injury with possibly less pronounced axonal damage.
Correlation of $\mathrm{SICl}$ and GCS

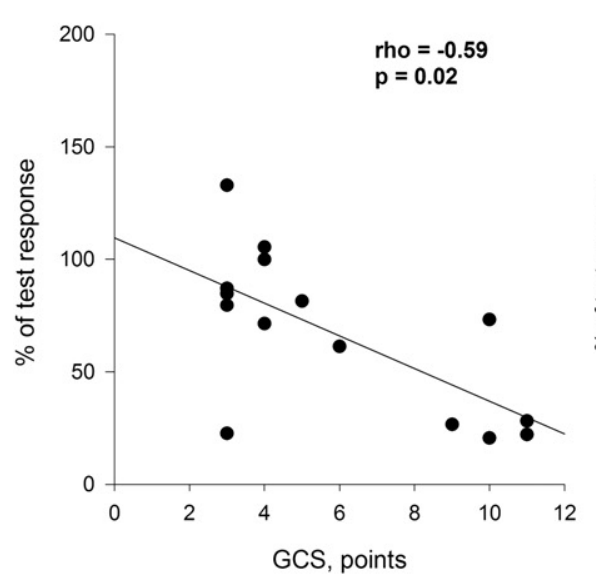

Correlation of SICI to FIM

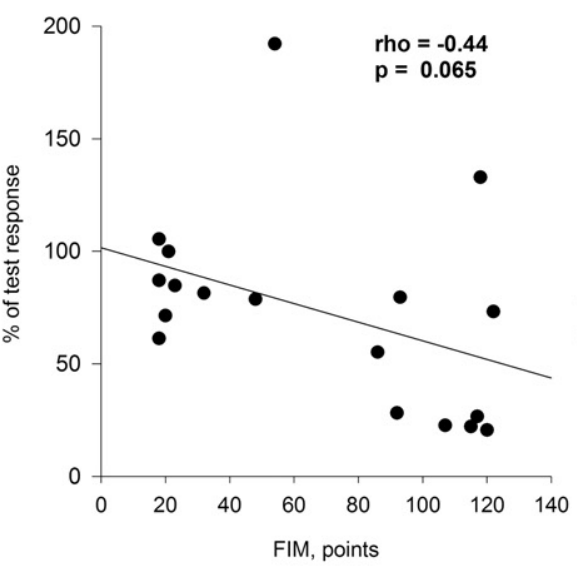

Correlation of SICI to RLAS

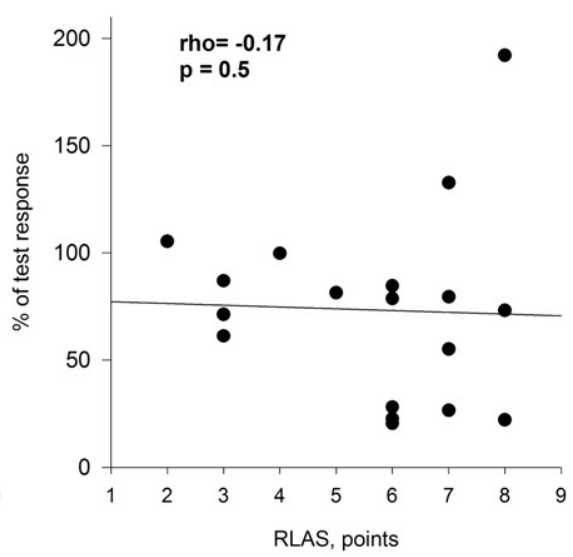

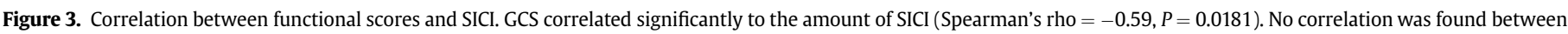

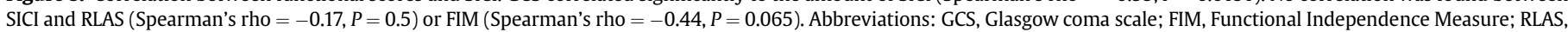
Ranchos Los Amigos Levels of Cognitive Functioning Assessment Scale; SICI, short intracortical inhibition. 


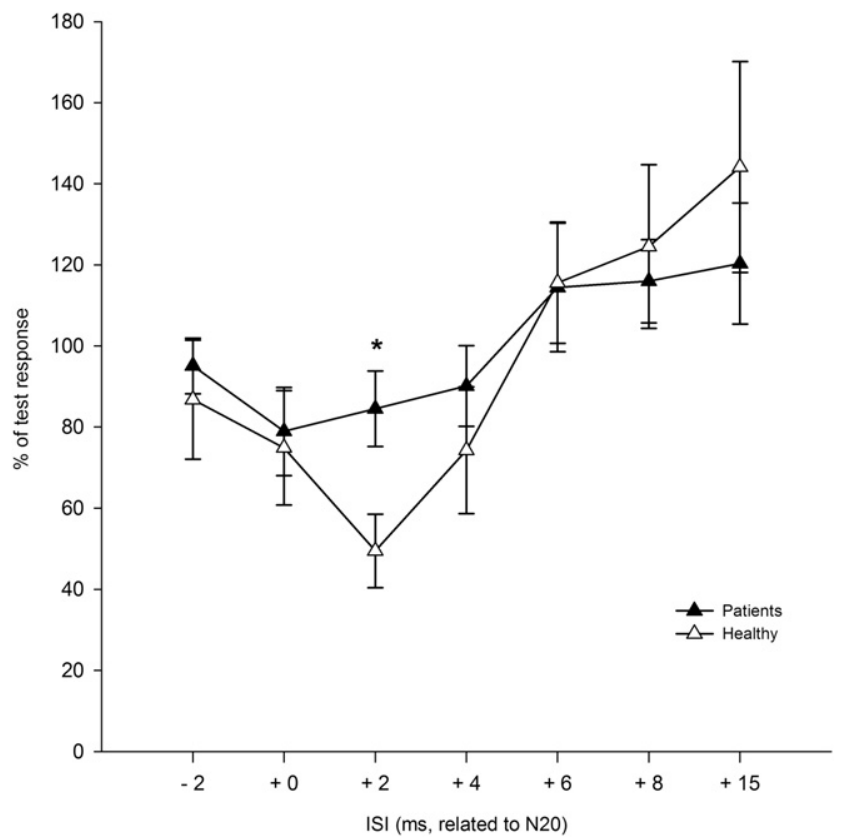

Figure 4. Short latency afferent inhibition by somatosensory input from the median nerve in patient (black triangles) and control group (open triangles). Ratios of mean conditioned/unconditioned MEP amplitude are plotted. Conditioning median nerve stimulation preceded TMS of the contralateral motor cortex by seven different ISIs, which were corrected for the latency of the N20 component of the somatosensory evoked potential in each subject. The data presented are mean values \pm SEM. Comparisons between time courses of the conditioning median nerve stimulation revealed significant difference between patient and control groups (two factor ANOVA with ISI $(F=9.88, P=0.0000)$ and group $(F=0.53, P=0.47)$ as the main factors and the interaction between them $(F=2.18, P=0.047)$. Post hoc analysis showed the most prominent difference between the groups when the median nerve stimulus was given at $\mathrm{N} 20+2 \mathrm{~ms}$ before the cortical stimulus $(P=0.027$, two-sample $t$-test). Abbreviations: MEP, motor evoked potential; ISI, interstimuli intervals.

\section{Limitations of the study}

It is important to highlight that the TMS measurements in the current study could be influenced by the centrally acting drugs administered to the patients (as standard care in the rehabilitation hospital). It has been shown that benzodiazepines can reduce ICF and SAI, and increase SICI [57], however, the influence of other centrally acting drugs on cortical excitability has not been thoroughly investigated. While some information has been gathered on how individual drugs influence TMS [65], the effects of different drug combinations, often used in severely brain damaged patients, remains unclear. Further studies without any central nervous system modulating medication would improve the understanding of the underlying pathophysiological mechanisms in brain injury. A second caveat relates to the presence of hydrocephalus, which might affect both functional status and TMS measurements. In the current study, seven patients had a ventricular enlargement confirmed with a CT or MRI examination and three of patients were treated with ventriculoperitoneal shunt. The patients had a diverse functional outcome with FIM scores varying from 18 to 118 . The effect of hydrocephalus and shunting on TMS parameters has not been thoroughly investigated. However, the study performed in patients with symptomatic hydrocephalus of different origin, showed MEP amplitudes and corticospinal conduction times within the normal range [66]. In the current study, we had only limited information on cerebrospinal fluid pressure at the time of the TMS investigation. However, none of the patients studied had the clinical signs of the elevated cerebrospinal fluid pressure. In future studies, confirmation of diffuse cerebral atrophy and secondary ventricular enlargement or presence of hydrocephalus with elevation of cerebrospinal fluid pressure is required. Finally, in the current study here was heterogeneity in the size, location, severity, and type of focal lesions in the participants with different brain injury aetiology. Future studies should correlate the amount of inhibition as measured by TMS with the abnormal brain anatomy in the corpus callosum, internal capsule, cerebral peduncle, and thalamus as measured using MRI (e.g. diffusion tensor imaging, fractional anisotropy, voxel-based morphometry). Nevertheless, this study provides detailed information on the integrity of the corticospinal sensorimotor pathways in patients with anoxic, traumatic, and non-traumatic diffuse brain injury.

In conclusion, the current study showed significantly reduced SICI and SAI in patients with anoxic, traumatic, and non-traumatic diffuse brain injury. Moreover, the significant correlation was found between the amount of intracortical inhibition and the severity of brain injury. Reduced cortical inhibition might suggest an impairment of the GABAergic and cholinergic systems in the primary sensorimotor cortex. Pharmacological studies with homogeneous brain injury populations would allow further assessment of this hypothesis, which, if confirmed, might offer prognostic surrogate markers and suggest novel therapeutic strategies.

\section{References}

[1] MacKenzie EJ. Epidemiology of injuries: current trends and future challenges. Epidemiologic Reviews 2000;22(1):112-9.

[2] Carter BG, Butt W. Are somatosensory evoked potentials the best predictor of outcome after severe brain injury? A systematic review. Intensive Care Medicine 2005 Jun;31(6):765-75.

[3] Young GB, Wang JT, Connolly JF. Prognostic determination in anoxic-ischemic and traumatic encephalopathies. Journal of Clinical Neurophysiology 2004 Sep-Oct;21(5):379-90.

[4] Kobayashi M, Pascual-Leone A. Transcranial magnetic stimulation in neurology. Lancet Neurology 2003 Mar;2(3):145-56.

[5] Lapitskaya N, Coleman MR, Nielsen JF, Gosseries O, de Noordhout AM. Disorders of consciousness: further pathophysiological insights using motor cortex transcranial magnetic stimulation. Progress in Brain Research 2009; 177:191-200.

[6] Schiene K, Bruehl C, Zilles K, Qu MS, Hagemann G, Kraemer M, et al. Neuronal hyperexcitability and reduction of $\operatorname{GABA}(\mathrm{A})$-receptor expression in the surround of cerebral photothrombosis. Journal of Cerebral Blood Flow and Metabolism 1996 Sep;16(5):906-14.

[7] Domann R, Hagemann G, Kraemer M, Freund HJ, Witte OW. Electrophysiological changes in the surrounding brain tissue of photochemically induced cortical infarcts in the rat. Neuroscience Letters 1993 May;155(1):69-72.

[8] Neumann-Haefelin T, Witte OW. Periinfarct and remote excitability changes after transient middle cerebral artery occlusion. Journal of Cerebral Blood Flow and Metabolism 2000 Jan;20(1):45-52.

[9] Mittmann T, Luhmann HJ, Schmidtkastner R, Eysel UT, Weigel H, Heinemann U. Lesioninduced transient suppression of inhibitory function in rat neocortex in vitro. Neuroscience 1994 Jun;60(4):891-906.

[10] Shimizu T, Hosaki A, Hino T, Sato M, Komori T, Hirai S, et al. Motor cortical disinhibition in the unaffected hemisphere after unilateral cortical stroke. Brain 2002 Aug;125:1896-907.

[11] Swayne OBC, Rothwell JC, Ward NS, Greenwood RJ. Stages of motor output reorganization after hemispheric stroke suggested by longitudinal studies of cortical physiology. Cerebral Cortex 2008 Aug;18(8):1909-22.

[12] Fujiki M, Hikawa T, Abe T, Ishii K, Kobayashi H. Reduced short latency afferent inhibition in diffuse axonal injury patients with memory impairment. Neuroscience Letters 2006 Sep 25;405(3):226-30.

[13] Chistyakov AV, Soustiel JF, Hafner H, Trubnik M, Levy G, Feinsod M. Excitatory and inhibitory corticospinal responses to transcranial magnetic stimulation in patients with minor to moderate head injury. Journal of Neurology Neurosurgery Psychiatry 2001 May;70(5):580-7.

[14] Chistyakov AV, Hafner H, Soustiel JF, Trubnik M, Levy G, Feinsod M. Dissociation of somatosensory and motor evoked potentials in non-comatose patients after head injury. Clinical Neurophysiology 1999;110(6):1080-9.

[15] Takeuchi N, Ikoma K, Chuma T, Matsuo Y. Measurement of transcallosal inhibition in traumatic brain injury by transcranial magnetic stimulation. Brain Injury 2006 Aug;20(9):991-6.

[16] Bernabeu M, Demirtas-Tatlidede A, Opisso E, Lopez R, Tormos JM, PascualLeone A. Abnormal corticospinal excitability in traumatic diffuse axonal brain injury. Journal of Neurotrauma 2009 Dec;26(12):2185-93.

[17] Talelli P, Greenwood RJ, Rothwell JC. Arm function after stroke: neurophysiological correlates and recovery mechanisms assessed by transcranial magnetic stimulation. Clinical Neurophysiology 2006 Aug;117(8):1641-59. 
[18] Koski L, Mernar TJ, Dobkin BH. Immediate and long-term changes in corticomotor output in response to rehabilitation: correlation with functional improvements in chronic stroke. Neurorehabilitation and Neural Repair 2004 Dec;18(4):230-49.

[19] Chistyakov AV, Soustiel JF, Hafner H, Elron M, Feinsod M. Altered excitability of the motor cortex after minor head injury revealed by transcranial magnetic stimulation. Acta Neurochirurgica 1998;140(5):467-72.

[20] Reid AE, Chiappa KH, Cros D. Motor threshold, facilitation and the silent period in cortical magnetic stimulation. In: Pascual-Leone A, Davey NJ, Rothwell J, Wassermann EM, Puri BK, editors. Handbook of transcranial magnetic stimulation. New York: Oxford University Press Inc; 2002. p. 97-111.

[21] Di Lazzaro V, Oliviero A, Profice P, Saturno E, Pilato F, Insola A, et al. Comparison of descending volleys evoked by transcranial magnetic and electric stimulation in conscious humans. Electromyography and Motor ControlElectroencephalography and Clinical Neurophysiology 1998;109(5):397-401.

[22] McDonnell MN, Orekhov Y, Ziemann U. The role of GABA(B) receptors in intracortical inhibition in the human motor cortex. Experimental Brain Research 2006;173(1):86-93.

[23] Tokimura H, Di Lazzaro V, Tokimura Y, Oliviero A, Profice P, Insola A, et al. Short latency inhibition of human hand motor cortex by somatosensory input from the hand. Journal of Physiology-London 2000;523(2):503-13.

[24] Maertens de Noordhout A, Rothwell JC, Day BL, Dressler D, Nakashima K, Thompson PD, et al. Effect of digital nerve stimuli on responses to electrical or magnetic stimulation of the human brain. Journal of Physiology-London 1992; 447:535-48.

[25] Di Lazzaro V, Oliviero A, Tonali PA, Marra C, Daniele A, Profice P, et al. Noninvasive in vivo assessment of cholinergic cortical circuits in AD using transcranial magnetic stimulation. Neurology 2002;59(3):392-7.

[26] Rossi S, Hallett M, Rossini PM, Pascual-Leone A. Safety, ethical considerations, and application guidelines for the use of transcranial magnetic stimulation in clinical practice and research. Clinical Neurophysiology 2009 Dec;120(12):2008-39.

[27] Teasdale G, Jennett B. Assessment of coma and impaired consciousness. A practical scale. Lancet 1974;2(7872):81-4.

[28] Hagen C, Malkmus D, Durham P. Levels of cognitive functioning. In: Downey CA, ed. Professional Staff Association of Rancho Los Amigos Hospital eds Rehabilitation of the head injured adult: comprehensive physical management: Rancho Los Amigos Hospital Inc 1987.

[29] Linacre JM, Heinemann AW, Wright BD, Granger CV, Hamilton BB. The structure and stability of the functional independence measure. Archives of Physical Medicine and Rehabilitation 1994;75(2):127-32.

[30] Puksa L, Stalberg E, Falck B. Reference values of F wave parameters in healthy subjects. Clinical Neurophysiology 2003;114(6):1079-90.

[31] Mills KR, Boniface SJ, Schubert M. Magnetic brain stimulation with a double coil: the importance of coil orientation. Electroencephalography and Clinical Neurophysiology 1992;85(1):17-21.

[32] Rossini PM, Berardelli A, Deuschl G, Hallett M, Maertens de Noordhout AM, Paulus W, et al. Applications of magnetic cortical stimulation. The international federation of clinical neurophysiology. Electroencephalography and Clinical Neurophysiology Supplement 1999;52:171-85.

[33] Kujirai T, Caramia MD, Rothwell JC, Day BL, Thompson PD, Ferbert A, et al. Corticocortical inhibition in human motor cortex. Journal of PhysiologyLondon 1993 Nov;471:501-19.

[34] Di Lazzaro V, Restuccia D, Oliviero A, Profice P, Ferrara L, Insola A, et al. Magnetic transcranial stimulation at intensities below active motor threshold activates intracortical inhibitory circuits. Experimental Brain Research 1998; 119(2):265-8.

[35] Liepert J, Storch P, Fritsch A, Weiller C. Motor cortex disinhibition in acute stroke. Clinical Neurophysiology 2000;111(4):671-6.

[36] Cicinelli P, Pasqualetti P, Zaccagnini M, Traversa R, Oliveri M, Rossini PM. Interhemispheric asymmetries of motor cortex excitability in the postacute stroke stage - a paired-pulse transcranial magnetic stimulation study. Stroke; A Journal of Cerebral Circulation 2003;34(11):2653-8.

[37] Di Lazzaro V, Profice P, Pilato F, Capone F, Ranieri F, Pasqualetti P, et al. Motor cortex plasticity predicts recovery in acute stroke. Cerebral Cortex 2010;20(7): 1523-8.

[38] Celnik P, Hummel F, Harris-Love M, Wolk R, Cohen LG. Somatosensory stimulation enhances the effects of training functional hand tasks in patients with chronic stroke. Archives of Physical Medicine and Rehabilitation 2007 Nov; 88(11):1369-76

[39] Butefisch CM, Netz J, Wessling M, Seitz RJ, Homberg V. Remote changes in cortical excitability after stroke. Brain 2003;126:470-81.

[40] Werhahn KJ, Kunesch E, Noachtar S, Benecke R, Classen J. Differential effects on motorcortical inhibition induced by blockade of GABA uptake in humans. Journal of Physiology- London 1999;517(2):591-7.

[41] Imbrosci B, Mittmann T. Functional consequences of the disturbances in the GABA Mediated inhibition induced by injuries in the cerebral cortex. Neural Plasticity 2011;2011:614329.
[42] Liepert J, Hamzei F, Weiller C. Motor cortex disinhibition of the unaffected hemisphere after acute stroke. Muscle and Nerve 2000 Nov;23(11):1761-3.

[43] Manganotti P, Patuzzo S, Cortese F, Palermo A, Smania N, Fiaschi A. Motor disinhibition in affected and unaffected hemisphere in the early period of recovery after stroke. Clinical Neurophysiology 2002 Jun;113(6):936-43.

[44] Kirkwood A, Bear MF. Hebbian synapses in visual cortex. Journal of Neuroscience 1994 Mar;14(3):1634-45.

[45] Harauzov A, Spolidoro M, DiCristo G, De Pasquale R, Cancedda L, Pizzorusso T, et al. Reducing intracortical inhibition in the adult visual cortex promotes ocular dominance plasticity. Journal of Neuroscience 2010 Jan; 30(1):361-71.

[46] Calautti C, Naccarato M, Jones PS, Sharma N, Day DD, Carpenter AT, et al. The relationship between motor deficit and hemisphere activation balance after stroke: a 3T fMRI study. NeuroImage 2007 Jan;34(1):322-31.

[47] Masanic CA, Bayley MT, vanReekum R, Simard M. Open-label study of donepezil in traumatic brain injury. Archives of Physical Medicine and Rehabilitation 2001;82(7):896-901.

[48] Taverni JP, Seliger G, Lichtman SW. Donepezil mediated memory improvement in traumatic brain injury during post acute rehabilitation. Brain Injury 1998;12(1):77-80.

[49] Oliviero A, Leon AM, Holler I, Vila JF, Siebner HR, Della Marca G, et al. Reduced sensorimotor inhibition in the ipsilesional motor cortex in a patient with chronic stroke of the paramedian thalamus. Clinical Neurophysiology 2005; 116(11):2592-8.

[50] Manganelli F, Ragno M, Cacchio G, Iodice V, Trojano L, Silvaggio F, et al. Motor cortex cholinergic dysfunction in CADASIL: a transcranial magnetic demonstration. Clinical Neurophysiology 2008;119(2):351-5.

[51] Selden NR, Gitelman DR, Salamon-Murayama N, Parrish TB, Mesulam MM. Trajectories of cholinergic pathways within the cerebral hemispheres of the human brain. Brain 1998;121:2249-57.

[52] Everitt BJ, Robbins TW. Central cholinergic systems and cognition. Annual Review of Psychology 1997;48:649-84.

[53] Di Lazzaro V, Pilato F, Dileone M, Saturno E, Oliviero A, Marra C, et al. In vivo cholinergic circuit evaluation in frontotemporal and Alzheimer dementias. Neurology 2006;66(7):1111-3.

[54] Metherate R, Ashe JH. Synaptic interactions involving acetylcholine, glutamate, and GABA in rat auditory cortex. Experimental Brain Research 1995; 107(1):59-72.

[55] Di Lazzaro V, Oliviero A, Profice P, Pennisi MA, Di Giovanni S, Zito G, et al Muscarinic receptor blockade has differential effects on the excitability of intracortical circuits in the human motor cortex. Experimental Brain Research 2000;135(4):455-61.

[56] Liepert J, Schardt S, Weiller C. Orally administered atropine enhances motor cortex excitability: a transcranial magnetic stimulation study in human subjects. Neuroscience Letters 2001;300(3):149-52.

[57] Di Lazzaro V, Oliviero A, Saturno E, Dileone M, Pilato F, Nardone R, et al. Effects of lorazepam on short latency afferent inhibition and short latency intracortical inhibition in humans. Journal of Physiology-London 2005;564(2):661-8.

[58] Nardone R, Bergmann J, Kronbichler M, Kunz A, Klein S, Caleri F, et al. Abnormal short latency afferent inhibition in early Alzheimer's disease: a transcranial magnetic demonstration. Journal of Neural Transmission 2008; 115(11):1557-62.

[59] Di Lazzaro V, Pilato F, Dileone M, Pfofice P, Marra C, Ranieri F, et al. In vivo functional evaluation of central cholinergic circuits in vascular dementia. Clinical Neurophysiology 2008;119(11):2494-500.

[60] Sakuma K, Murakami T, Nakashima K. Short latency afferent inhibition is not impaired in mild cognitive impairment. Clinical Neurophysiology 2007; 118(7):1460-3.

[61] Homberg V, Stephan KM, Netz J. Transcranial stimulation of motor cortex in upper motor neuron syndrome: its relation to the motor deficit. Electroencephalography and Clinical Neurophysiology 1991;81(5):377-88.

[62] Moosavi SH, Ellaway PH, Catley M, Stokes MJ, Haque N. Corticospinal function in severe brain injury assessed using magnetic stimulation of the motor cortex in man. Journal of Neurological Sciences 1999 Apr 1;164(2):179-86.

[63] Di Lazzaro V, Oliviero A, Profice P, Ferrara L, Saturno E, Pilato F, et al. The diagnostic value of motor evoked potentials. Clinical Neurophysiology 1999 Jul;110(7):1297-307.

[64] Magistris MR, Rosler KM, Truffert A, Landis T, Hess CW. A clinical study of motor evoked potentials using a triple stimulation technique. Brain 1999;122: 265-79.

[65] Paulus W, Classen J, Cohen LG, Large CH, Di Lazzaro V, Nitsche M, et al. State of the art: pharmacologic effects on cortical excitability measures tested by transcranial magnetic stimulation. Brain Stimulation 2008;1(3):151-63.

[66] Roricht S, Meyer BU, Woiciechowsky C, Lehmann R. Callosal and corticospinal tract function in patients with hydrocephalus: a morphometric and transcranial magnetic stimulation study. Journal of Neurology 1998 May;245(5): 280-8. 